\title{
Slow wins: patience, perseverance and behavior change
}

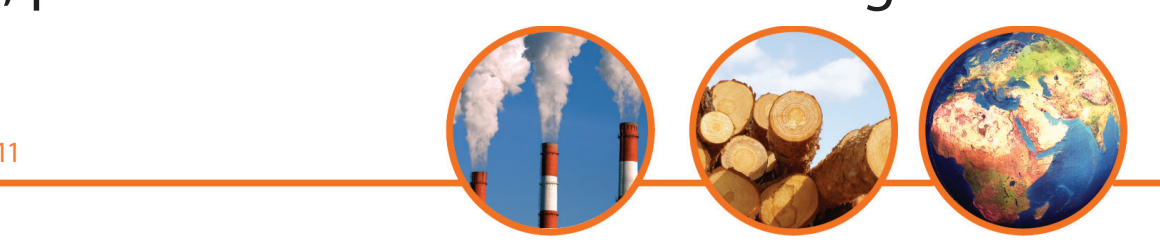

C6 The transition we face must be done well the first time with the changes made durable; it is unlikely we will get a second chance. 99

Raymond De Young*

Keywords: adaptive muddling $\boldsymbol{m}$ behavior change $\boldsymbol{\|}$ behavioral continuity $\boldsymbol{\|}$ behavioral wedges $\boldsymbol{\|}$ demand reduction

- durable change $\mathbf{m}$ environmental psychology $\boldsymbol{\|}$ human nature $\boldsymbol{\|}$ innate inclinations $\boldsymbol{\|}$ intrinsic satisfactions

The converging of climate disruption, energy descent and economic instability is stressing civilization, perhaps foreshadowing a downshift to a lower level of complexity [1]. It is easy to despair at the unsustainability of human behavior; however, such despair may come from taking too narrow and pessimistic a view of human nature, such as believing:

- Unsustainability results from a motivational drive to reduce cognitive dissonance, which leaves us floundering in collective denial;

- Behavioral inertia is an immutable force making us unable to shift direction;

- Much of human behavior is reducible to the actions of one neurotransmitter; our demise will result from hijacking dopamine pathways;

- Humans are egocentric, short-term gain maximizers, consuming resources with little concern for waste, passing costs on to others and forming exclusive groups that neglect outsiders.

While each is based on valid insights, the mistake is our believing that any one is the root of human nature.
Such reductionism harkens, unfortunately, to an earlier period, when a then-dominant behaviorism argued that the existence of a behaviorist explanation made all other explanations irrelevant. This notion that an explanation at one level usurps the possibility of a useful explanation at another was widespread enough to have received several colorful labels, such as 'nothing butism' and MacKay's more elegant "fallacy of 'nothing buttery"'.

After over a century of research, it would hardly seem necessary for us to argue in support of multiple determinants of behavior. Yet, single-determination theories abound. Their oversimplification is no more acceptable now than it was then; if indeed there is a demonstrable role for one view, this in no way eliminates the possibility that there is a role for other, and more positive, views as well. That humans can act in unsustainable ways is irrefutable. But when discussing human behavior, saying that our species' motivation is $\mathrm{X}$ or our behavior is to always do $\mathrm{Y}$ is simply wrong. There is no scientific basis for so narrow a view of human nature. The brain is more malleable and behavior more adaptive than such statements allow. 
The fallacy is compounded by the advice that typically follows: due to the alleged unsustainability of human nature, people's behavior must be manipulated; they must be managed using incentives, disincentives and tight prescriptive rules, and the content of their mental models (e.g., attitudes, knowledge and worldview) must be reformed. The flaw here is our assumed privilege as reformation experts. With rhetorical and condescending questions (e.g., are humans smarter than yeast?) we dismiss the possibility of the public voluntarily changing behavior in time to avoid catastrophe. But strangely, as experts, we are held above this contempt. We arrogate to ourselves a rarefied psychological nature and a noble obligation to make other people behave. Alas, even if this assumed entitlement is granted, research shows that the manipulations we commonly employ are not reliable and rarely durable [2].

We must correctly define the problem being faced. The issue here is not whether human nature leads inexorably to sustainable or unsustainable outcomes; we are capable of both, neither is inevitable. What we are challenged with is specifying the conditions under which humans behave more reasonably [3].

\section{Behavior is hard to change, but its stability is good}

Behavioral inertia is mentioned as a serious barrier to the changes needed [4]. However, we should recoil at inertia's alternative: behavior being extremely easy to change, creating great moment-to-moment variability. Every next stimulus, whether from the environment or others, distracts attention and diverts behavior. Behavior changed never stays changed for long. Clearly, this describes a chaotic system, one unable to follow a plan or achieve a goal.

The irrationality of the alternative makes it easy to see why continuity of behavior is an adaptive trait. Without it our existence would be incoherent. The real concern here is that our current behavior is maladaptive, not its resistance to change. If extremely low-energy living was the norm, then we would welcome its stability.

Behavioral inertia is also a feature essential to successful carbon management. Consider the wedge concept for keeping carbon in check [5] and, in particular, the behavioral version that can provide three of the seven wedges needed by changing everyday household activities [6]. This approach already includes an expectation of behavioral continuity. When viewed as a century-long process, two things emerge. Most wedges must expand over time to further reduce carbon emissions and, more important behaviorally, changes that are adopted must stay adopted. We already expect relative permanence in changes made to infrastructure and policies, and in fuel switching. But the wedges of behavior-driven demand reduction also require long-term continuity. Thus, behavioral stability, far from being an obstacle, becomes a feature that we will come to rely on; we must learn to leverage it.

\section{Behavior emerges from a complex information-} processing system

A common social change theory begins with natural science specifying the problem and needed solution, leading to policies seeking to change behavior. It is easy to see the missing element here. Behavior emerges from complex structures in the brain; interventions from science-policy interactions are but one of many inputs to this system.

The brain is an astonishingly complex informationprocessing system, involving approximately $10^{11}$ neurons and $10^{14}$ synapses, forming a massive neural network with emergent properties. It does not only store experience but also contains inherited structures and tendencies. In this system, behavior is rarely a predetermined response to input stimuli. It proved adaptive to place cognition between stimulus and response, and to allow it to mediate our emotions. The effect of this adaptation is an astounding ability. It allows us to override automatic functioning, whether based on innate stimulus-driven patterns (e.g., inherited inclinations), learned patterns (e.g., habits) or affect. We can contemplate alternate explanations for events, consider multiple responses and explore initially weak alternatives instead of jumping to first conclusions. These mental skills are foundational, allowing us to make plans, carry them out and behave with civility [7]

We might sometimes seem like a conflicted species, with tension among cognition, instinct and emotion, and stymied by behavioral continuity. Yet, we can reframe this tension and inertia as equipoise: a capacity to calmly monitor the environment, our thoughts, intentions and possible behaviors, all while correcting any preconceptions. Such a capability did not have to evolve, but it did. Because of it, humans can steadfastly pursue goals in complex, changing and emotionally charged environments. Unfortunately, it also makes changing people's behavior a slow and humbling process.

\section{The multiple causes offer behavior change} options

We have a great many options for changing behavior but seem only to emphasize a few. To see what we are missing, consider three categories of psychological constructs, each varying in the degree to which they remain stable over time:

- Category 1: Included here are such constructs as attitudes, and both declarative knowledge (i.e., know 
why) and procedural knowledge (i.e., know how). We focus most of our attention here both in our efforts to change these variables and in lamenting their weakness in effect and their instability over time (e.g., attitudes change and knowledge fades). The wavering of attitudes about climate change [8] recently caused concern. But such change is predictable. For instance, the recent drop in support of global warming as a national priority in the USA occurred at a time of dramatic competition for our attention (e.g., a national election and a great recession). However, even without competition, it is common for constructs in this category to vary over time, since they are labile. This instability is appreciated by the public themselves; when asked about their attitudinal certainty, only those at the extremes of attitude about climate change (i.e., alarmed or dismissive) reported that they were unlikely to change their mind [9];

- Category 2: A collection of more stable constructs including norms (social, personal, descriptive and injunctive) [10], various aspects of sense of responsibility and efficacy (self and group) and intrinsic satisfactions (competence, frugality and participation) [2]. The modification of cultural norms provides insight about the speed of enduring change. Humans have witnessed the changing of many norms including establishing the rights of common people versus the monarchy, the elimination of enslavement as an acceptable practice and the emergence of civil rights. More recent examples include increase in seatbelt usage and cessation of smoking in most venues. There is no guarantee that changes in norms are permanent, but there is a conservative inclination at work here reflecting a universal human concern for predictability [11]. One common feature, and a lesson we might draw, is that normative change happens slowly; some changes take centuries and most take at least several decades;

- Category 3: This slow-to-change notion applies all the more to the third category of constructs that have pronounced stability. These deep cognitive structures, which include such things as values, worldviews, virtues and character strengths (e.g., wisdom, courage, humanity, justice, temperance and transcendence) [12], ought to be hard to change. If they changed easily and/or often, we might take it as a sign of pathology, certainly as a sign that the person is not trustworthy.

These examples are far from exhaustive; many other psychological constructs exist, each offering a means to influence behavior. But even the few constructs mentioned give a sense for the broad space within which we can affect behavior. Furthermore, research offers an unusual logic at work here: none of them alone are sufficient, none are necessary, yet all are useful. Only a few are easily manipulated and even fewer lend themselves to a top-down approach. In addition, in what is perhaps a key issue for environmental stewardship, they have varying relationships with durable behavior. If we start with continuity of behavior as our goal, then we might ask how tightly connected each category is with such behavior. While no such fixed wiring exists in the brain owing to its plasticity, there are plausible relationships. The first category would be only weakly related to enduring behavior, while the second and third categories would be more tightly connected. Thus, it seems that if we seek behavior change that sticks then we should emphasize the latter two categories. Unfortunately, this has not been our approach.

Commonly, when seeking to change behavior, we focus on a small set of strategies directed at the first category. We attempt to alter people's attitudes or try to educate them. We use instructional, informational and media campaigns, or use rules, regulations and incentives. Yet, if these strategies worked as well as we had hoped and needed them to, then we would not need to consider the other categories. Certainly, the failure here rests not with human nature but on too narrow an approach to changing behavior. These common strategies tend to be top-down, delivery-based approaches. Such efforts to induce change often fail because the message, as delivered, fails to connect with the existing mental models, goals and inclinations of the intended receivers. Rather than trying to insert our ideas, beliefs and goals into the minds of others we should help people to build their own understanding of the situation [13], a slow but sure strategy.

Less commonly we focus on the second category, altering the context of behavior or making aspects of that context more salient (e.g., linking behavioral opportunities to innate concerns and motives). The strategies used here include social and norm marketing, persuasion and, less frequently, the aforementioned rules, regulations and incentives. While still delivery based, there is a greater appreciation of the information exchange that goes on in person-environment interactions. Humans are often trying to discover what is expected of them, what they will be competent at doing and what behaviors are compatible with their deeper motives and goals. The strategies used seek to make such discovery easier.

It is uncommon to attend to the third category. Strategies here seek to activate and amplify inherited inclinations. A delivery-based approach makes no sense; we must facilitate involvement as a lifelong enterprise. We still alter the context of behavior but with the intent 
of creating conditions that support long-term cognitive engagement. Change emerges slowly because it is understood that participation, while essential, cannot be forced or rushed.

\section{Slow wins for lasting change}

There are a number of fascinating approaches being developed that are based on up-to-date models of human behavior. They utilize all three categories described above but emphasize the latter two. Some of the more interesting approaches are derived from Lewin's pioneering work on using citizen meetings, first to present people with the problem and then to give them the time and support needed to develop local solutions [14]. An excellent update, targeted for environmental stewardship, was done by Matthies and Kromker [15]. Examples that show great promise include a community-based intervention called Ecoteams [16] and a recent approach that leverages intrinsic values [17].

The arguments for our not just accepting, but embracing slow change and a modest role for experts such as ourselves, have been developed by a number of researchers $[18,19]$. However, it would be wrong to think that small experiments and slow change mean that only small steps can be taken. A behavior-change process called adaptive muddling stresses this subtle but important difference [20]. When contemplating their response, people need not privilege the status quo by investigating only marginal behavior change. The rate of adoption may be slow but this process supports people exploring, and thus prefamiliarizing themselves with, life-changing adaptations. Furthermore, while the impact from any one group's change may be modest, the process supports simultaneously exploring many changes at once, each drawing on the knowledge and experience people already have (suggesting the importance of listening, an activity easily neglected when we believe it urgent to change others' behavior). People are thus empowered to apply local and personal knowledge to a situation, creating a variety of locally compatible responses.

Behavior change happens but durable change happens only slowly. What is unnerving is that our environmental problems are urgent, perhaps accelerating. This might give rise to intolerance for the slow-change notion being suggested. But, in fact, the opposite response is needed from us. The transition we face must be done well the first time with the changes made durable; it is unlikely we will get a second chance.

Thus, what is called for is a balance between urgency and patience. Urgency is a matter of established fact for anyone well informed, but the need for patience is rarely mentioned. This need emerges from understanding that the less-used strategies, such as facilitating participation or altering the social context of behavior, produce stable but slow-to-emerge behavior.

As experts, we seem prone to a deep cynicism about the prospect of changing behavior in time to avert catastrophe. It would seem, then, that what needs to change first is something in us. We can anticipate the aid of behavioral continuity as we alter social norms and leverage existing values. But to be of real help, we need to draw upon our own character strengths of courage to be patient with the process of behavior change, and steadfastness to persevere through the doubt that others hold about human nature.

\section{Financial \& competing interests disclosure}

The author has no relevant affiliations or financial involvement with any organization or entity with a financial interest in or financial conflict with the subject matter or materials discussed in the manuscript. This includes employment, consultancies, honoraria, stock ownership or options, expert testimony, grants or patents received or pending, or royalties. No writing assistance was utilized in the production of this manuscript.

\section{References}

1 Tainter J. Social complexity and sustainability. Ecological Complexity 3, 91-103 (2006).

$>_{2}$ De Young R. Expanding and evaluating motives for environmentally responsible behavior. J. Soc. Issues 56, 509-526 (2000).

- 3 Kaplan S, Kaplan R. Creating a larger role for environmental psychology: the Reasonable Person Model as an integrative framework. J. Environ. Psychol. 29, 329-339 (2009).

World Bank. World Development Report: Development and Climate Change. World Bank Publications, Washington, DC, USA (2010).
Pacala S, Socolow R. Stabilization wedges: solving the climate problem for the next 50 years with current technologies. Science 305, 968-972 (2004).

-6 Dietz T, Gardner G, Gilligan J, Stern P, Vandenbergh M. Household actions can provide a behavioral wedge to rapidly reduce US carbon emissions. Proc. Natl Acad. Sci USA 44, 18452-18456 (2009).

7 De Young R. Restoring mental vitality in an endangered world. EcoPsychology 2, 13-22 (2010).

8 Leiserowitz A, Maibach E, Roser-Renouf C. Climate Change in the American Mind: Public Support for Climate \& Energy Policies in January 2010. Yale University and George
Mason University, New Haven, CT, USA (2010).

9 Leiserowitz A, Smith N. Knowledge of Climate Change Across Global Warming's Six Americas. Yale University, New Haven, CT, USA (2010)

10 Cialdini R. Crafting normative messages to protect the environment. Curr. Dir. Psychol. Sci. 12, 105-109 (2003).

11 Cantril H. The human design. In: The Pattern of Human Concerns. Rutgers University Press, New Brunswick, NJ, USA (1966).

12 Peterson C, Seligman M. Character Strengths and Virtues: a Handbook and Classification. Oxford University Press, Oxford, UK (2004). 
13 Kaplan R, Kaplan S. Bringing out the best in people: a psychological perspective. Conserv. Biol. 22, 826-829 (2008).

14 Lewin K. Group decision and social change. In: Readings in Social Psychology. Swanson GE, Newcomb TM, Hartley EL (Eds). Henry Holt and Company, New York, USA, 459-473 (1952).

15 Matthies E, Kromker D. Participatory planning: a heuristic for adjusting interventions to the context. J. Environ. Psychol. 20, 65-74 (2000).
16 Staats H, Harland P, Wilke H. Effecting durable change: a team approach to improve environmental behavior in the household. Environ. Behavior 36, 341-367 (2004).

17 Sheldon K, Nichols C, Kasser T. Americans recommend smaller ecological footprints when reminded of intrinsic American values of self-expression, family, and generosity. EcoPsychology 3, 97-104 (2011).

18 Weick K. Small wins: redefining the scale of social problems. Am. Psychol. 39, 40-49 (1984).
19 Irvine K, Kaplan S. Coping with change: the small experiment as a strategic approach to environmental sustainability. Environ. Manag. 28, 713-725 (2001).

20 De Young R, Kaplan S. Adaptive muddling. In: The Localization Reader: Adapting to the Coming Downshift. De Young R, Princen T (Eds). The MIT Press, Cambridge, MA, USA, 287-298 (2012). In press. 